\title{
Food foments European disunity
}

Could biotechnology erode the European ideal? It does seems unlikely, doesn't it? The European Community has grown continuously for forty years. The European Union (EU), as it has now become, encompasses 15 member states (from six originally) and over 350 million people. And a united Europe can even beat the US at golf. But when it comes to foods containing genetically manipulated organisms (GMOs), the European nations seem to want to return to insularity and argument.

Single markets are one of the most fundamental of EU aims: One set of consumer reassurances on safety and quality standards for products, and one set of regulatory requirements for manufacturers across the EU. What companies and consumers now face is 15 standards and 15 regulations.

The European Commission has striven to make a single market for all new foods. A Europe-wide measure, the Novel Foods Regulations, was introduced in May this year. But it was too sketchy: It defined "a novel food" as something that was not "substantially equivalent" to a food that was on the market already.

Although most of industry did not realize it at the time, it was this phrase- "substantial equivalence"- that meant that foods containing GMOs would have be labeled as such. But the legislators did not define what would make them "novel." A recombinant tomato that produces an extra protein and is sold fresh is arguably a novel food. But what about an antisense tomato which turns off a gene? What if the recombinant food is heated to denature any protein; is that still "substantially equivalent?" And what if a recombinant crop is used for edible oil, as is the case with soya?
The Novel Food Regulations also didn't say how foods must be "equivalent" and how "equivalent" they must be. Any requirement for absolute identity is clearly impractical; even peas in a pod are not actually alike. The European Commission proposed two options for establishing the "nonequivalence" of genetically engineered foods; detection of either the distinguishing proteins or the introduced DNA. However, both were rejected at the beginning of November by a committee of officials drawn from the member states' governments. The committee failed to consider the form of words to be used on the labels considered. No surprise then that European Commission officials threw up their hands in desperation. If the member states cannot agree on a system to make a single market, they say, we cannot impose one.

Companies now have to interpret the Novel Foods Regulations in their own way, decide what and how to test, how to apply the results, and what wording, if any, to use on labels. That might sound like an ideal free market, but it is not. The regulators from the individual nations of Europe-yes, the same folks who didn't agree on what tests to use-are also free to interpret the regulations as they want. By failing create a single market, they have held on to regulatory power.

This will, of course, create a great deal of confusion. Companies using biotechnology products will stumble into controversies about labeling and testing. Opponents of genetic engineering will continue to fuss, monitoring "GMO-free" product claims and calling for this or that type of label. Trading wars will stem from the "genism" of the EU. But at least the national civil servants will still have their jobs.

\section{The yeast genome yields its secrets}

It's no surprise that the power of DNA chip technology to simultaneously examine the differential expression of every gene of an entire organism has first been demonstrated using Saccharomyces cerevisiae (see $\mathrm{p}$. 1359 and Science 278:680-686). S. cerevisiae is the model single cell organism for geneticists as well as for cell and molecular biologists. Comparing the properties of the mRNA from spatially or temporally related sources (e.g., in diseased versus normal tissue) should allow the identification of genes involved in the phenotypic difference. As a result, functional genomics in drug discovery is now not only reasonable, but a huge step closer to becoming practical. What's more, the approach will work for any organism whose genome has been sequenced.

But yeast differential expression analysis is not just a step, it is a possible solution to the last major problem in the application of functional genomics to food and microbial biotechnology. For bakers, brewers, and enologists, yeast is not the model, it is the target. Paul Attfield reviews (see p. 1351) one major key to the success of industrial baker's yeast - its ability to withstand a variety of environmental stresses. Yeast stress tolerance has largely been achieved by selection and classical genetics. And although the technology to manipulate the yeast genome has been available for decades, recombinant DNA techniques have largely been ignored for improving food yeast. Why is that? Perhaps because of fears of consumer reluctance toward foods made from genetically engineered strains. More importantly, an engi- neering approach has not been possible. Stress is a simple term to describe a complex series of events that can differ greatly. Under any given growth condition, it is not obvious which genes are involved in the stress response. It is unrealistic to believe that the manipulation of the expression of single genes would improve tolerance; rather, Attfield points out it is likely multiple genes will be involved.

This brings us to the "massive analysis" of yeast gene expression. In the genome-wide differential display of Lockhart and colleagues, gene expression in cells grown in minimal medium was compared with that of cells grown in rich medium. The result illustrates the power of the technology to identify genes (whether or not the function is known) that are turned on in specific environmental circumstances. The accuracy with which an environmental stress can be recreated in the laboratory will determine the quality, and usefulness, of the results obtained. Such data sets should provide yeast metabolic and genetic engineers with the necessary inputs to intelligently design improvements. Assumptions about the pathways to be targeted can now be replaced by empirical observations.

Chip technology for differential display will eventually find its prominent place in the arsenal of medical diagnostic and drug discovery tools. But right now it can be used to define, select, and engineer any single-cell organism whose genome has been sequenced, for the myriad of nonmedical applications that also are biotechnology. 